\title{
Sulong Kabataan: Design, Pilot Implementation, and Evaluation of a Youth Substance Abuse Prevention Program
}

\author{
Danielle P. Ochoa ${ }^{1}$ \\ Lorelie Ann Banzon-Librojo ${ }^{2}$ \\ Samantha Erika N. Mendez ${ }^{1,2}$ \\ Liane Peña Alampay ${ }^{2}$ \\ ${ }^{1}$ University of the Philippines, Diliman \\ ${ }^{2}$ Ateneo de Manila University
}

\begin{abstract}
Substance abuse prevention is especially important during adolescence given the propensity of young people to take risks during this period. Although prevention programs have been developed and widely evaluated in other countries, they are costly and have not been adapted to the Filipino context. We developed Sulong Kabataan as a community-based life skills program for substance abuse prevention among urban Filipino youth. We discuss the program design process, pilot implementation, and evaluation among 53 adolescents aged 12 to 17 from a low-resource community. The evaluation of the pilot implementation demonstrates the feasibility of the program, especially with close community partnerships. Preliminary evidence for positive impact was shown in participants' life skills and confidence to refuse alcohol. The strengths of the program include the interactive delivery and positive learning climate, as well as facilitators' warmth and competence informed by knowledge of adolescent development. Future directions are discussed for improving the program design and evaluation, and developing training programs for facilitators.
\end{abstract}

Keywords: adolescence, substance abuse prevention, life skills training, youth prevention programs, refusal skills

Correspondence concerning this article can be addressed to Danielle P. Ochoa, Department of Psychology, Lagmay Hall, Roxas cor. Africa Sts., University of the Philippines, Diliman, Quezon City 1101. Email: dpochoa@up.edu.ph 
Substance use poses great risks during adolescence given the simultaneous biological, cognitive, and social changes taking place during this period (Steinberg, 2005). For instance, adolescent substance use is associated with cognitive deficits such as poor memory, attention, concentration, spatial skills, and executive functioning (Ibrahim, Mahmud, Abubakar, Harazini \& Abdulkadir, 2016; Squeglia, Jacobus, \& Tapert, 2009) that may lead to immediate negative effects on language competence and school performance, and more lasting effects on adolescents' maturing brains (Chassin, Hussong, \& Beltran, 2009). Furthermore, early adolescent use of cigarettes, alcohol, and marijuana, sometimes known as gateway substances, has been associated with increased risk of later use of illicit drugs (Kandel, 2002) and substance abuse disorders (DeWit, Adlaf, Offord, \& Ogborne, 2000).

Recent statistics on a nationally representative sample of Filipino youth reported that about $30.1 \%$ of $15^{-}$to 19 -year-olds drank alcohol, $15.6 \%$ smoked cigarettes, and $2.6 \%$ had tried using drugs (Demographic Research and Development Foundation [DRDF] \& University of the Philippines Population Institute [UPPI], 2014). Apart from actual substance use, young people are likely to be exposed to various illicit substances in their environment. In the National Capital Region alone, about 92\% of the barangays are said to have citizens who use illicit drugs (Philippine Drug Enforcement Agency [PDEA], 2015). This environment combined with the potential harm of substances on adolescent development makes prevention programs especially important in this life stage. Programs of this nature focus on strengthening protective factors and reducing risk factors to promote positive developmental outcomes (Hawkins, Catalano, \& Miller, 1992). Given this context, we developed Sulong Kabataan, a culturallyand developmentally-appropriate life skills training program for substance abuse prevention to strengthen adolescents' capacities to avoid substance use, with its theoretical framework adapted from Botvin's (2000) Life Skills Training Program. This paper discusses the development, pilot implementation, and evaluation of the program among Filipino youth in low-resource communities, examining preliminary changes in outcomes such as life skills, refusal confidence, and substance use. 


\section{Youth Substance Abuse Prevention Programs}

Youth prevention programs come in different forms: indicated prevention for high-risk individuals, selective prevention for groups at-risk, and universal programs for the general population (Mrazek \& Haggerty, 1994). We focus on universal programs for adolescent substance use prevention, given their emphasis on primary prevention and the assumption that many youth in low-resource communities tend to be at-risk for substance use (Chassin et al., 2009). Several meta-analyses and systematic reviews converge on the important elements of universal prevention for adolescents (Das, Salam, Arshad, Finkelstein, \& Bhutta, 2016; Griffin \& Botvin, 2010; Onrust, Otten, Lammers, \& Smit, 2016). In terms of content, programs that successfully reduce substance use focus on personal and social skills, address social influence, and provide accurate information about the consequences of and misconceptions about substances. Program delivery is most effective when done by trained facilitators in a series of sessions using interactive methods where participants have opportunities to demonstrate and practice personal and social skills. Specific strategies include making public commitments to not use substances, mentoring, peer education, and involving parents, schools, and the community (Das et al., 2016). Importantly, these components consider the developmental characteristics of adolescence such as heightened social conformity and stress, and clarification of personal goals and identities (Onrust et al., 2016).

Among the programs most evidently demonstrating all of these components is Botvin's (2000) Life Skills Training Program, which has strong empirical evidence for its effectiveness in reducing adolescent substance use (Botvin \& Griffin, 2004, 2014). This program is founded on the theory that youth become less motivated to use drugs and less vulnerable to social influences when they have strong social and self-management skills, and develop healthier attitudes, normative expectations, and behaviors in relation to drugs when provided with social resistance skills. We discuss this program, which provides the foundations for Sulong Kabataan, in the latter section on program development.

Notably, Botvin's Life Skills Training program, along with 
majority of the programs reviewed in the aforementioned studies are implemented in high-income countries, implying the need for more rigorous program evaluations to be conducted in low- and middle-income countries (LMICs; Das et al., 2016). A review of youth substance abuse prevention programs in Asia revealed limitations in the number of programs and the quality of evaluations of such programs (Shek \& Yu, 2011). In this review, the authors found some effective school-based anti-smoking programs in China, Taiwan, and India, as well as community-based and multi-media drug prevention programs in China, Taiwan, and Hong Kong that improved students' knowledge and attitudes towards drug use. In the Philippines, existing school-based programs focus more on providing information about substances (Quijano, Quiambao, \& Papa, n.d.). An exception is a life skills drug prevention program developed and implemented in a public secondary school (Duka-Pante, 2017). Components of the program include open communication, assertiveness and refusal, handling negative peer pressure, critical thinking, and decision-making skills. However, the program has yet to be evaluated formally and extended beyond the particular school's setting (Duka-Pante, 2017).

In sum, this review demonstrates the components of standardized, evidence-based prevention programs that aim to reduce substance use and associated risk factors. However, most of these programs were developed and implemented mainly in Western settings, and have yet to be adapted and tested in the Philippine context. Many of these are likewise based in schools, limiting their impact to youth enrolled in the formal educational system. Moreover, these standardized programs involve costly training fees, making them inaccessible for implementation in LMICs. The appropriateness of youth prevention programs for the cultural setting is especially important to ensure fit with the intended audience (Gonz, Barrera, \& Martinez, 2004). Interventions used in LMICs should target risk factors associated with the outcomes to be prevented, be cost-effective, have evidence for effectiveness, and be feasibly brought to scale to minimize harm and wasting of limited resources (Ward, Sanders, Gardner, Mikton, \& Dawes, 2016).

In response to these limitations, we developed Sulong Kabataan, a community-based life skills program for Filipino adolescents for 
substance abuse prevention. The current program was developed with the Filipino adolescents' unique developmental needs in mind, such as the continued strength of parental authority and influence (Alampay, 2014) and centrality of family duties and responsibilities in their identities (Garo-Santiago, Mansukhani, \& Resureccion, 2009). It is designed to be implemented at the community level and focuses on teaching Filipino adolescents social and life skills to lessen their motivation to use and increase their capacity to refuse substances. In this paper, we first describe the process of developing the Sulong Kabataan program. This is followed by a presentation of the results of our pilot implementation and pre and posttest evaluation, which aim to assess the feasibility of the program in low-resource communities, identify strengths and areas of improvement, and guide the development of training programs for facilitators.

\section{PHASE 1: PROGRAM DEVELOPMENT}

\section{Method}

Developing Sulong Kabataan involved several steps: a needs analysis at the community level, review of existing prevention programs, drafting of the program modules, and a design and consultation workshop with stakeholders. A qualitative approach with multiple data sources was utilized to guide program development. We obtained ethics approval from the University Research Ethics Committee. Likewise, all research and program staff adhered to a Child Protection and Referral Protocol.

Needs analysis. The needs analysis aimed to understand the situation and psychosocial needs of Filipinoyouth. Trained interviewers conducted semi-structured interviews with 20 participants aged 13 to 17 years old from a low-resource community, and whose families are beneficiaries of the Pantawid Pamilyang Pilipino Program (4Ps), a poverty alleviation and social development program of the Philippine government. Beneficiaries of 4Ps are given cash grants provided they comply with conditions such as enrolling their children in school, maintaining class attendance, undergoing regular health checks, and participating in family development sessions. Participants were 
recruited by members of the Barangay Council for the Protection of Children (BCPC) using purposive sampling, ensuring a balance of participants' age and gender, with a large enough sample to bring about diverse responses. The interviews focused on issues and problems of the youth in the community, knowledge of and experience with drug use, and factors that may promote and prevent drug use.

Two separate focus group discussions (FGDs) were also conducted with seven mothers of the adolescent participants and 11 barangay officials and workers who worked with youth in the community. In forming the groups, we aimed for balance of diverse perspectives and a manageable number that would still allow for participation of all members. Mothers were asked about their concerns regarding their own children, the youth in their community, and drug-related issues. Barangay officials and workers were asked about youth problems in the community, drug-related issues and data, existing community programs, and relevant ordinances.

Review of prevention programs and module design. We identified common elements of evidence-based substance use and abuse prevention programs, namely: Botvin's (2004) Life Skills Training program, Economic and Social Commission for Asia and the Pacific/United Nations Office on Drugs and Crime (ESCAP/UNODC) Life Skills Training Guide for Young People on HIV/AIDS \& Substance Abuse Prevention (ESCAP, 2003), UNODC Family Skills Training Program (UNODC, 2009), Strengthening Families Program (Kumpfer, Alvarado, \& Whiteside, 2003), Towards no Drug Abuse (Sussman, 1996), Project ALERT (Ghosh-dastidar, Longshore, Ellickson, \& Mccaffrey, 2004), and Katatagan Kontra Droga sa Komunidad (Psychological Association of the Philippines, 2017). This review yielded a number of recurring content areas among the programs: stress management, emotion regulation, communication, problem solving in relationships, refusal skills, and goal-setting. Notably, these revolve around self-management, social skills, and drug resistance skills, which served as the backbone of the Sulong Kabataan program framework (see Table 1). This framework was adapted mainly from Botvin's (2000) Life Skills Training program, which had clearly laid out the model components and outcomes, and had strong empirical support on its effectiveness (Botvin, 2000; Botvin \& Griffin, 2004, 


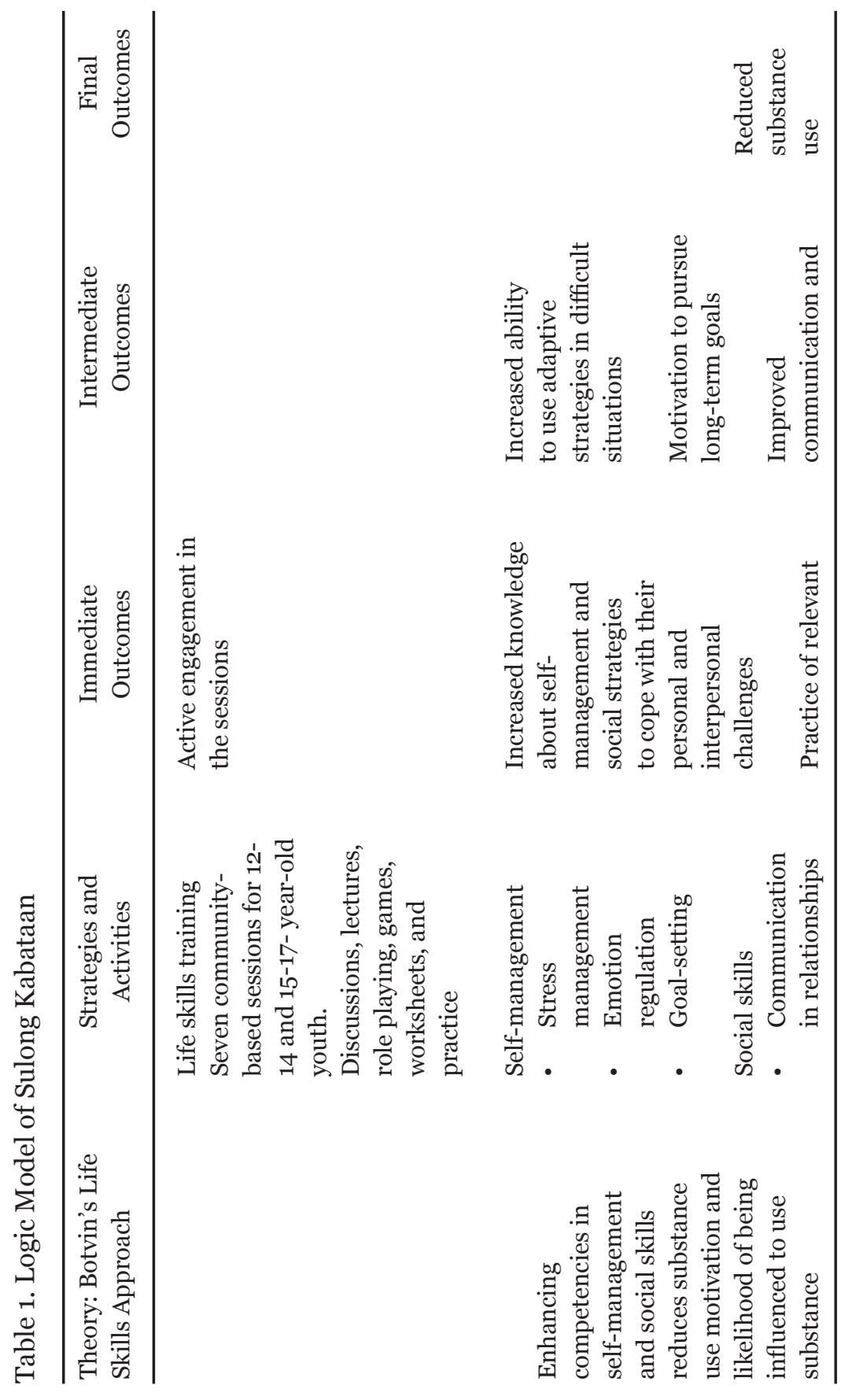




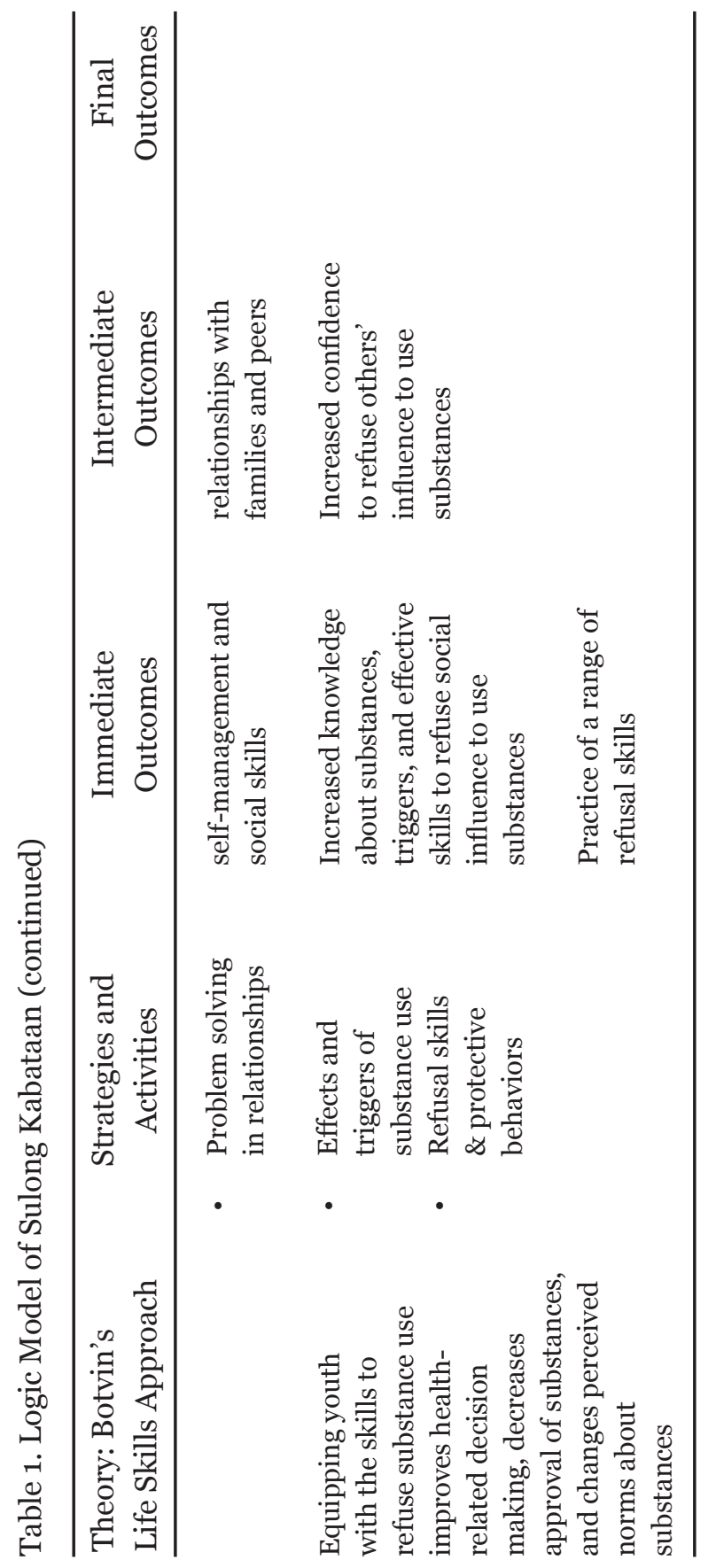


2014).

The modules were developed by adapting elements from the various programs reviewed while ensuring that the content and approaches were grounded on the results of the needs analysis with Filipino youth, parents, and barangay officials, the developmental capacities of adolescent participants, the sociocultural context, and practical considerations of community-based implementation.

Consultation with stakeholders. After initial module development, a consultation workshop with various stakeholders was conducted to validate and obtain feedback on the program design and discuss important considerations for program implementation and delivery. Participants were four barangay officials and representatives from the BCPC, one public school guidance counselor, members of the City's Anti-Drug Abuse Advisory Council, volunteers from the Diocese, five members of the City Police District, two drug abuse and prevention professionals, and four developmental and clinical psychologists. Participants assessed the appropriateness of module objectives, methodologies, themes, and materials, considering the logic model and the results from the needs analysis of the Filipino youth. Through small group discussions, participants provided inputs on the modules' strengths and areas of improvement, and important considerations in program implementation. The modules were revised further following stakeholders' recommendations.

\section{Results}

Needs analysis. Both adolescent and adult participants reported youth concerns with family conflicts, school problems, finances, and substance use involving not only drugs but also cigarettes and alcohol. Responses reveal the need to gain a deeper understanding of substance use, have positive relationships, and develop internal resources for the prevention of substance abuse (see Table 2 for summary of results and modules where these are addressed).

Salience of negative effects of drug use. Youth participants identified some immediate rewards of using drugs (e.g., feeling happy and invincible), but were more aware of its negative effects. They cited both immediate consequences, such as loss of control and logic 
Table 2. Key Findings of Needs Analysis and Implications for Module Design

\begin{tabular}{|c|c|}
\hline Findings From Needs Analysis & Module \\
\hline $\begin{array}{l}\text { Lack of understanding on the } \\
\text { immediate effects of drugs }\end{array}$ & Effects and triggers of substances \\
\hline \multicolumn{2}{|l|}{ Identified reasons for drug use } \\
\hline Interpersonal conflicts & $\begin{array}{l}\text { Communication in relationships } \\
\text { Problem solving in relationships }\end{array}$ \\
\hline Negative thoughts and emotions & $\begin{array}{l}\text { Stress management } \\
\text { Emotion regulation }\end{array}$ \\
\hline $\begin{array}{l}\text { Attraction to substances due to } \\
\text { curiosity or enjoyment }\end{array}$ & $\begin{array}{l}\text { Effects and triggers of substances } \\
\text { Refusal skills and protective } \\
\text { behaviors }\end{array}$ \\
\hline \multicolumn{2}{|l|}{ Identified protective factors } \\
\hline Loving and supportive relationships & $\begin{array}{l}\text { Communication in relationships } \\
\text { Problem solving in relationships }\end{array}$ \\
\hline Behavioral strategies & $\begin{array}{l}\text { Stress management } \\
\text { Emotion regulation } \\
\text { Refusal skills and protective } \\
\text { behaviors }\end{array}$ \\
\hline $\begin{array}{l}\text { Internal resources (e.g., values, } \\
\text { goals, character strengths) }\end{array}$ & $\begin{array}{l}\text { Stress management } \\
\text { Emotion regulation } \\
\text { Goal-setting }\end{array}$ \\
\hline
\end{tabular}

and increased likelihood to commit crime, and long-term effects, including deterioration of physical and mental health, breakdown of relationships, incarceration or institutionalization, inability to reach ambitions, and financial losses. Death was also mentioned as a possibility, due to the effects of the drug, suicide, or being killed. Given these negative effects, some participants wondered why people even use drugs. These findings suggest the need for more clarity on the realistic effects of substance use. 
Psychosocial reasons for drug use. Participants, be it youth, parents, or barangay officials and workers surmised that people use drugs because of familial conflict and lack of love, guidance, and support from parents. Conflict with peers and romantic relationships, as well as enticement from peers and older people in the community, were also considered influential. All three sets of participants also pointed to specific psychological reasons for drug use such as negative thoughts and emotions (e.g., feeling stressed, sad, hopeless, unloved, or useless) and attraction to substances due to curiosity or the enjoyment it brings.

Positive relationships and personal resources as protective factors. Both youth and adult participants believed that loving and supportive relationships, as well as guidance from parents, friends, and role models were essential for protecting the youth from substance abuse. They also cited behavioral strategies such as avoiding substances and users, engaging in positive activities (e.g., studies, sports, exercise), and seeking support. Additionally, participants also considered the importance of personal resources including cognitive processes such as thinking of negative consequences of substance use on self and others, valuing life and hard work, and setting goals; and character strengths (e.g., discipline, self-confidence, willpower). These internal resources must be developed to strengthen youths' ability to address personal problems. Adult participants, both parents and barangay representatives, likewise identified the importance of institutional support to address root causes, develop drug-related programs, and provide youth activities.

The findings from the needs analysis guided the design of six modules that would help participants deal with stresses and emotions, communicate and solve problems in relationships, resist pressure to use substances, and set goals for the future. Importantly, these findings emphasized the centrality of building life skills for strengthening relationships as a protective factor for young people, leading us to integrate relationships more heavily in the program.

Consultation workshops. Feedback from stakeholders led to refinements in the program towards greater developmental appropriateness and a more holistic approach, and raised important considerations for selecting and training facilitators. 
Developmental considerations. Stakeholders affirmed the strength of the life skills approach for adolescent development. In considering the participants' age and socioeconomic status, however, stakeholders emphasized the need to deliver the concepts in simple and less formal language, define key processing questions, and use clearer instructions. Suggested improvements included using more appropriate stimulus materials (e.g., a less technical video on the effects of drugs), more relevant and relatable situations pertaining to school or peer concerns, and employing interactive and engaging activities like games, physical activities, weighing pros and cons, and creative presentations. Eliciting inputs from adolescents was likewise considered a better approach than simply providing didactic information. For instance, stakeholders suggested providing participants with scenarios instead of scripts to demonstrate coping or resistance strategies.

Module components. Stakeholders recommended a more holistic approach to each life skill. For instance, they suggested focusing on physical, emotional, cognitive, and behavioral effects of stress, considering both overt and covert manifestations of emotions, and tackling both verbal and non-verbal communication. They likewise suggested separating the components of the module on refusal skills, with one module focusing on the effects and triggers of substance use, and another for practicing refusal skills.

Stakeholders emphasized the need for handouts and homework to allow participants to review and practice skills independently in relevant situations. They suggested beginning each session with a recap of previous learnings and discussion of take home tasks, and being explicit about the relevance of specific activities (e.g., mindfulness) for the life skill tackled in each session. Finally, they recommended that sessions must always end on a positive note.

Important facilitator qualities. Stakeholders highlighted the importance of selecting qualified and committed facilitators for successful implementation of the program. Facilitators must be able to establish rapport and work well with young people through good communication, teaching, and facilitating skills. They should also be knowledgeable, accepting, and non-judgmental of adolescents. Time management, combined with flexibility, is important to adroitly pace 
the activities as necessary. Facilitators should also be able to detect and appropriately handle or refer problematic cases. All of these require sufficient training and practice.

In sum, the consultation workshop led to revisions to make the program more relevant, engaging, and understandable by using more constructive than didactic approaches, simplifying content, and using additional age-appropriate instructional materials and strategies. These results also contributed to a more holistic approach to each life skill, considering their multiple psychological components, and expanding some content such as those on effects and triggers of substances and refusal skills. It also highlighted the qualities and skills important for selection and training of facilitators.

The Sulong Kabataan Program: A life skills program for substance abuse prevention. From the aforementioned process and results, we developed Sulong Kabataan as a community-based life skills program for substance abuse prevention by strengthening adolescents' self-management, social, and refusal skills (see Table 1 for the logic model). It was created with the developmental features of adolescence in mind, and informed largely by Botvin's Life Skills Training (LST) program, which heavily emphasized the skill areas that converged with the needs analysis and stakeholder workshop (Botvin, 2000; Botvin \& Griffin, 2004, 2014). The program uses interactive methods such as group discussions, brief direct instruction, behavioral rehearsal, giving feedback, affirming and strengthening self-efficacy, extended practice, and repetition.

The program has seven modules building on each other: stress management, understanding and responding to emotions, communication in relationships, decision making and problem solving, effects and triggers of using cigarettes, alcohol, and drugs (CAD), refusal skills and protective behaviors, and goal-setting (see Table 3 for the objectives of each). Each session starts with checking in followed by a mindfulness exercise, a review of the previous session, processing of homework, introduction of the new session, the module proper, sharing of insights, and assignment of homework. The pilot implementation and evaluation will be described in the succeeding section. 
Table 3. Modules and Objectives

\begin{tabular}{|c|c|}
\hline Module & Objectives \\
\hline 1. Stress management & $\begin{array}{l}\text { 1. Identify the sources of one's stress } \\
\text { 2. Examine the effects of stress on } \\
\text { one's body, emotions, actions, and } \\
\text { thoughts } \\
\text { 3. Identify positive ways to respond to } \\
\text { stress } \\
\text { 4. Practice awareness and relaxation } \\
\text { exercises }\end{array}$ \\
\hline $\begin{array}{l}\text { 2. Understanding } \\
\text { and Responding to } \\
\text { Emotions }\end{array}$ & $\begin{array}{l}\text { 1. Identify basic emotions } \\
\text { 2. Analyze their responses to intense } \\
\text { emotions } \\
\text { 3. Practice appropriate responses to } \\
\text { emotions, particularly applying } \\
\text { positive thinking }\end{array}$ \\
\hline $\begin{array}{l}\text { 3. Communication in } \\
\text { Relationships }\end{array}$ & $\begin{array}{l}\text { 1. Discuss the importance of clear and } \\
\text { effective communication } \\
\text { 2. Demonstrate how to effectively } \\
\text { communicate in various situations } \\
\text { 3. Use different strategies in sending } \\
\text { and receiving messages to maintain } \\
\text { positive relationships }\end{array}$ \\
\hline $\begin{array}{l}\text { 4. Decision Making and } \\
\text { Problem Solving in } \\
\text { Relationships }\end{array}$ & $\begin{array}{l}\text { 1. Discuss the common problems or } \\
\text { issues adolescents experience in } \\
\text { their relationships with other people } \\
\text { 2. Identify the steps in problem solving } \\
\text { 3. Choose appropriate strategies } \\
\text { in solving problems in their } \\
\text { relationships } \\
\text { 4. Practice using these strategies in } \\
\text { solving relationship problems }\end{array}$ \\
\hline $\begin{array}{l}\text { 5. Effects and Triggers } \\
\text { of Using Cigarettes, } \\
\text { Alcohol, and Drugs or } \\
\text { CAD }\end{array}$ & $\begin{array}{l}\text { 1. Identify general effects of using CAD } \\
\text { on people } \\
\text { 2. Discuss possible reasons behind use } \\
\text { of CAD }\end{array}$ \\
\hline
\end{tabular}


Table 3. Modules and Objectives (continued)

\begin{tabular}{|c|c|}
\hline Module & Objectives \\
\hline & $\begin{array}{l}\text { 3. Identify people, places, things, and } \\
\text { events that trigger use of CAD }\end{array}$ \\
\hline 6. Refusal Skills and & 1. Identify strategies to refuse $\mathrm{CAD}$ \\
\hline Protective Behaviors & $\begin{array}{l}\text { 2. Examine the appropriate refusal } \\
\text { strategy in various situations }\end{array}$ \\
\hline \multirow{4}{*}{$\begin{array}{l}\text { 7. Goal-Setting and } \\
\text { Looking to the Future }\end{array}$} & 3. Practice various refusal strategies \\
\hline & $\begin{array}{l}\text { 1. Identify the meaning and } \\
\text { importance of having goals for one's } \\
\text { future }\end{array}$ \\
\hline & $\begin{array}{l}\text { 2. Set their goals and plans for the } \\
\text { future }\end{array}$ \\
\hline & $\begin{array}{l}\text { 3. Analyze the connections of what } \\
\text { they learned in the modules for their } \\
\text { future plans }\end{array}$ \\
\hline
\end{tabular}

PHASE 2: PILOT IMPLEMENTATION AND EVALUATION

\section{Method}

Pilot implementation of Sulong Kabataan was conducted in an urban low-resource barangay for eight consecutive Saturdays. Two of this paper's authors facilitated each session and trained representatives from the barangay served as co-facilitators. Each session ran for approximately 1.5 to 2 hours and was evaluated by trained process observers. After each session, facilitators and process observers discussed what worked well in the session and what aspects were less effective, noting the necessary revisions for each module.

A mixed methods pretest-posttest design was applied to evaluate the feasibility of the Sulong Kabataan program, its preliminary outcomes, and strengths and areas for improvement. Quantitative data were obtained from measures of participants' life skills, confidence to refuse substance use, and patterns of substance use via structured interviews. Qualitative data included postintervention feedback from 
the participants, process observer notes, and facilitator observations and self-evaluations.

Participants. Fifty-seven adolescents initially enrolled in the program and responded to pretest measures. However, only 55 completed the program, which was defined as participation in at least five out of seven sessions, and 53 completed both pre and posttests. The 53 adolescents ranged in age from 12 to 17 , with 29 females and 24 males. Participants were recruited by the BCPC through purposive sampling on the basis of their age, families being beneficiaries of the 4Ps, and to the best of the barangay workers' knowledge, non-use of illegal drugs. They were clustered in four different groups, with two consisting of 12- to 14-year-olds with 15 participants each, and two consisting of 15 - to 17 -year-olds with 12 and 13 participants.

Before the program proper, participants and their parents attended an orientation to inform them about the nature of the program, potential risks and benefits, and emphasize the voluntary nature of their participation. Informed consent from the parents or guardians and assent from the youth participants were obtained prior to testing and program implementation.

Procedure. Adolescents who gave their assent and whose parents gave informed consent to participate in the program and the research took part in the pretest interview. Trained psychology graduate students conducted structured face-to-face interviews with the participants. Posttest interviews were conducted two weeks after the final session in a manner similar to the pretest, along with additional open-ended questions soliciting program feedback. Confidentiality was ensured by removing identifiers from all data and analyzing and reporting in aggregate. The responses from 53 adolescents with complete data were included in the analyses.

Measures. Pre and posttest measures were adapted from existing scales, translated from English to Filipino, back-translated, and subsequently pilot tested (see Table 4 for scale descriptive statistics and reliabilities).

Life Skills Scale. A 15-item Life Skills Scale was adapted from Sharma (2003) and Brown, Miller, and Lawendowski (1999) to assess life skills corresponding to identified learning objectives of the modules. Three items were used to assess each of the following 
life skills: stress management ("I can identify the sources of my stress"), managing emotions ("I understand how emotions can affect behaviors"), communication skills ("I know how to communicate effectively using words and actions"), problem solving in relationships ("I can think of solutions to difficult problems"), and goal setting ("It is important for me to have a goal for the future"). Participants rated their agreement on a 5 -point scale $(1=$ Really not true for me, $5=$ Really true for me). Scale scores were computed as the average of the 15 items, taken as an overall indicator of adaptive life skills. Internal consistency indices (i.e., Cronbach's alpha) for the individual life skills were low and were thus not analyzed by dimension.

Confidence to refuse substance use. Refusal confidence was measured using items adapted from Project ALERT Survey of Student Attitudes and Responses (Ghosh-dastidar et al., 2004). Using a 4-point scale ( 1 = No confidence, $4=$ Very confident), participants indicated their perceived efficacy to refuse smoking, drinking, and using drugs when: 1) their best friend is smoking; 2) their date is smoking; 3) they are bored at a party; and 4) all their friends are smoking at a party. Separate scores were computed for each substance using the means of the four items.

Patterns of substance use. Patterns of substance use pertain to past month use of substances, the approximate amounts, and the perceived likelihood of smoking or drinking alcohol in the next six months. Past month use was measured by asking, "How many days did you smoke cigarettes/drink alcohol in the past month?” (o, 1-2, or 3-5 days); approximate amount through the questions, "On the days when you smoke/drink, how much do you usually consume?” (cigarettes: less than 1, 1-2 sticks, 2 to 7 sticks; alcohol: a few sips, half a drink, one drink, three or more), and perceived likelihood of use in the next six months with, "Do you think you will smoke cigarettes/drink alcohol in the next six months?" (Definitely yes, probably yes, probably no, definitely no). These items were adapted from Project ALERT (Ghoshdastidar et al., 2004). Given the sample size restrictions, we could not test for differences in pre and posttest reports of substance use. As such, we will only be describing the observed patterns from pre to posttest.

Qualitative program evaluation. Trained researchers used 
a short interview guide to elicit participants' program evaluations and identity strengths and areas for improvement. They were asked the following open-ended questions in Filipino: 1) What did you learn from the program? 2) Which modules did you find helpful? How did these help you? 3) Which modules did you find less helpful? Why? 4) Which modules did you find difficult? Why? 5) What did you like about the modules/ activities/facilitators? 6) What didn't you like about the modules/activities/facilitators? 7) What changes do you suggest to improve the modules? What other activities would you suggest?

Data analysis. Quantitative data were analyzed using paired sample t-tests comparing pre and posttest scores. Qualitative data, on the other hand, were analyzed using conventional content analysis (Hsieh \& Shannon, 2005). This approach required immersion in the data, creating an initial coding scheme for key ideas, sorting them into meaningful categories, and identifying exemplars from the data. Three members of the research team conducted the analysis, and obtained consensus on the codes and categories created. Data extracts quoted from participants were translated from Filipino to English.

\section{Results}

Quantitative results. Table 4 presents the results of the paired samples t-tests on the pretest and posttest scores. Participants demonstrated increases in self-ratings of life skills after having undergone the program $(t(52)=-3.42, p=.001, d=.47)$. Aside from increases in life skills, participants also reported greater confidence to refuse alcohol in social situations $(t(52)=-2.61, p=.012, d=.36)$. Note that compared to refusal confidence with other substances, participants reported the lowest confidence to refuse alcohol in both pretest and posttest. However, overall refusal confidence, and confidence to refuse cigarettes and drugs did not change significantly after the program.

We observed trends towards the desired direction in participants' perceived likelihood of future substance use, and mixed results for reported substance use in the past month. In particular, fewer participants thought themselves to be likely to use both alcohol and cigarettes in the next six months, with fewer reporting "probably yes" and more reporting "definitely no" at posttest compared to pretest 


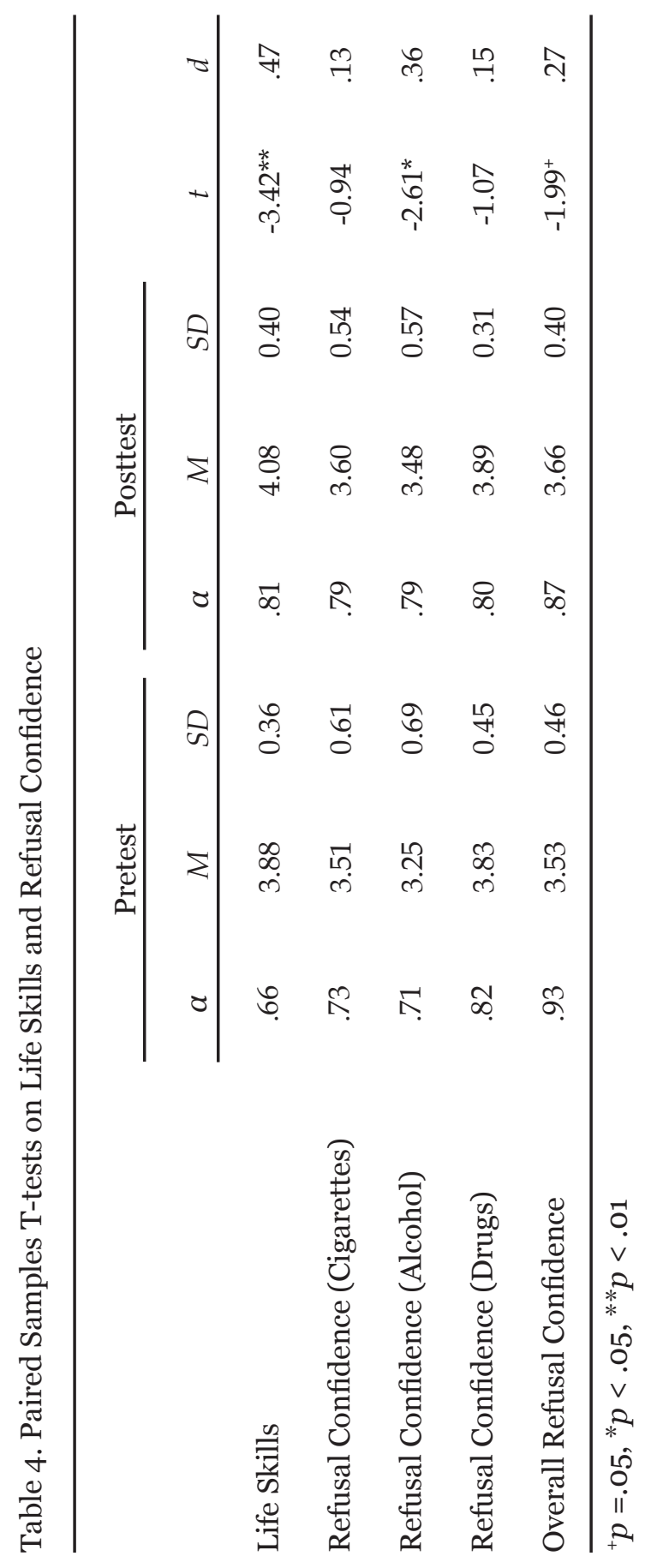


(see Figure 1). By contrast, there appeared to be an increase from pre to posttest in the number of participants who reported smoking and drinking in the past month (see Figure 2). In terms of amount used, there appears to be increased cigarette consumption (see Figure 3), with more participants who said they had smoked 1-2 sticks and fewer

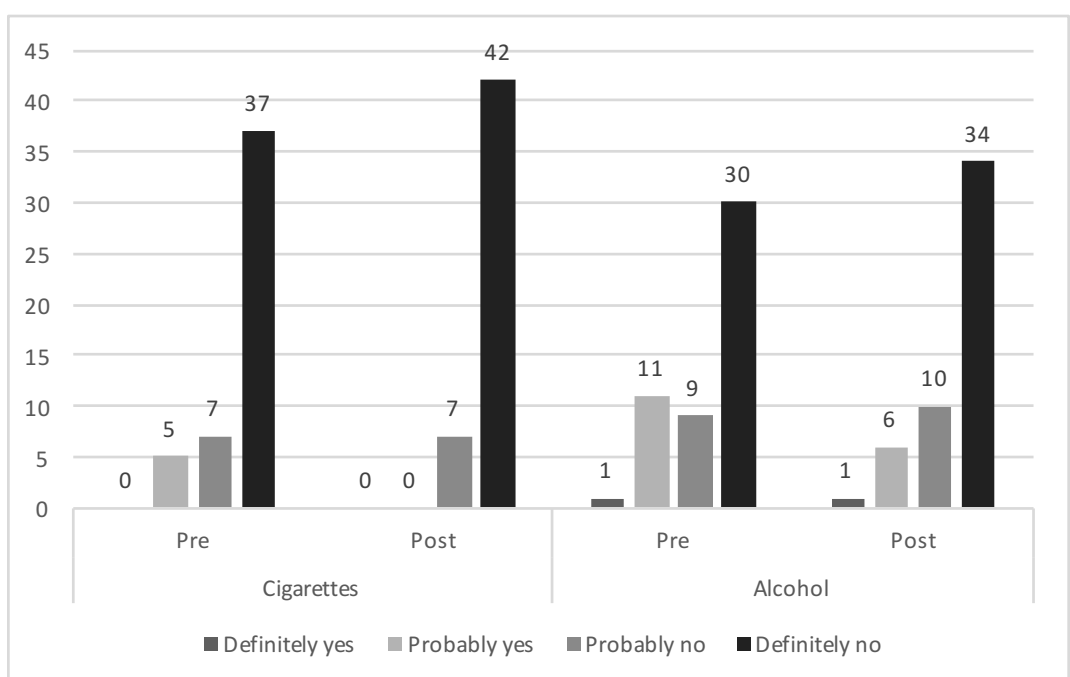

Figure 1. Number of participants indicating perceived likelihood of smoking and drinking

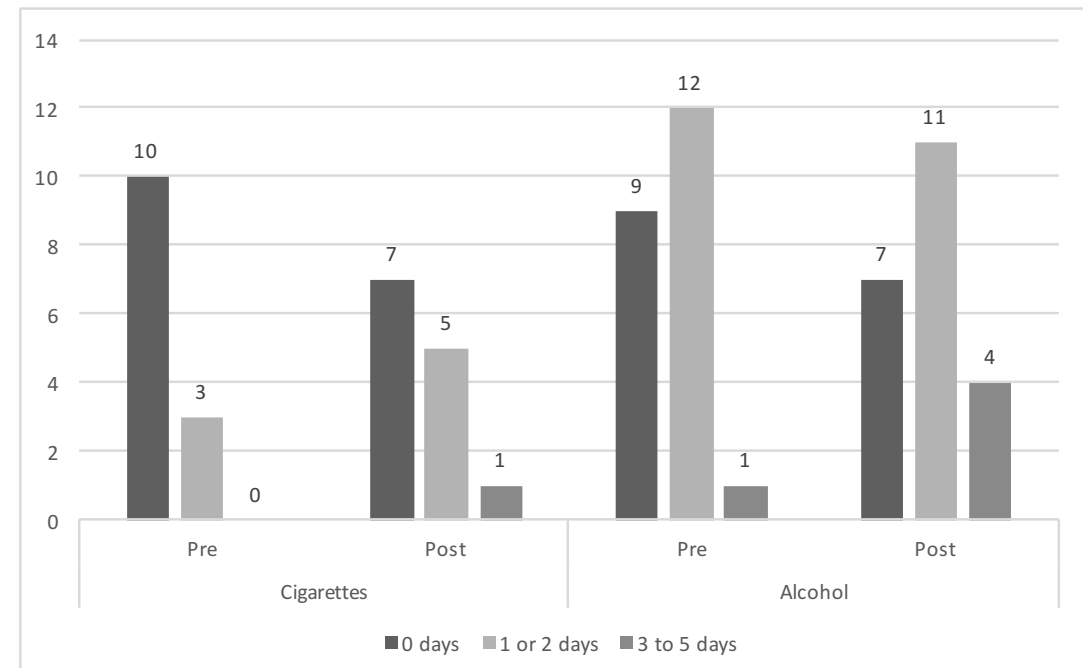

Figure 2. Number of participants reporting use of cigarettes and alcohol in the past month 


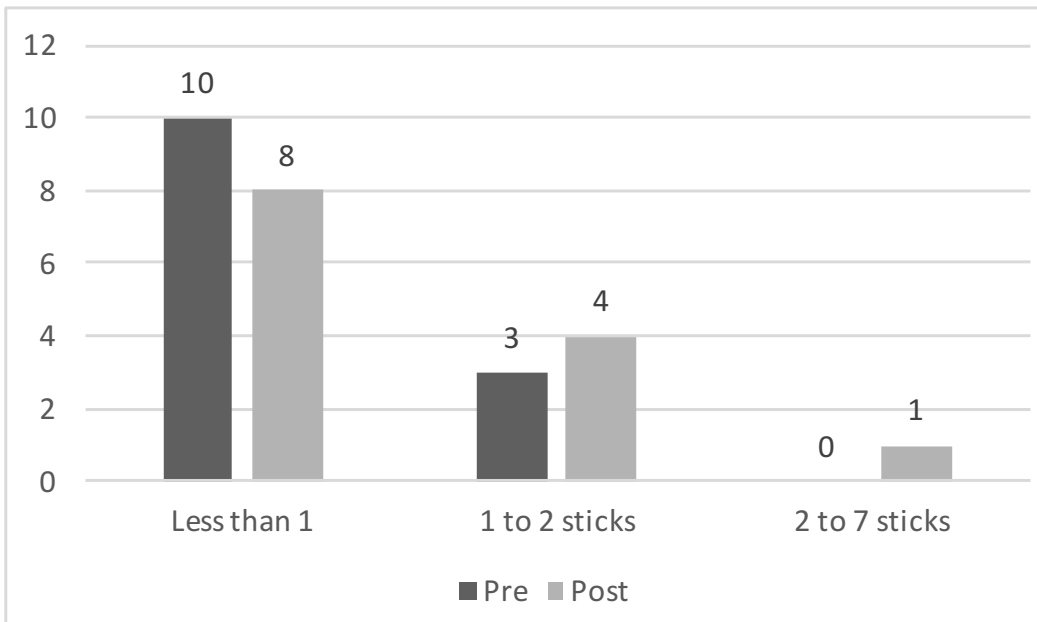

Figure 3. Number of participants reporting number of sticks of cigarettes typically consumed

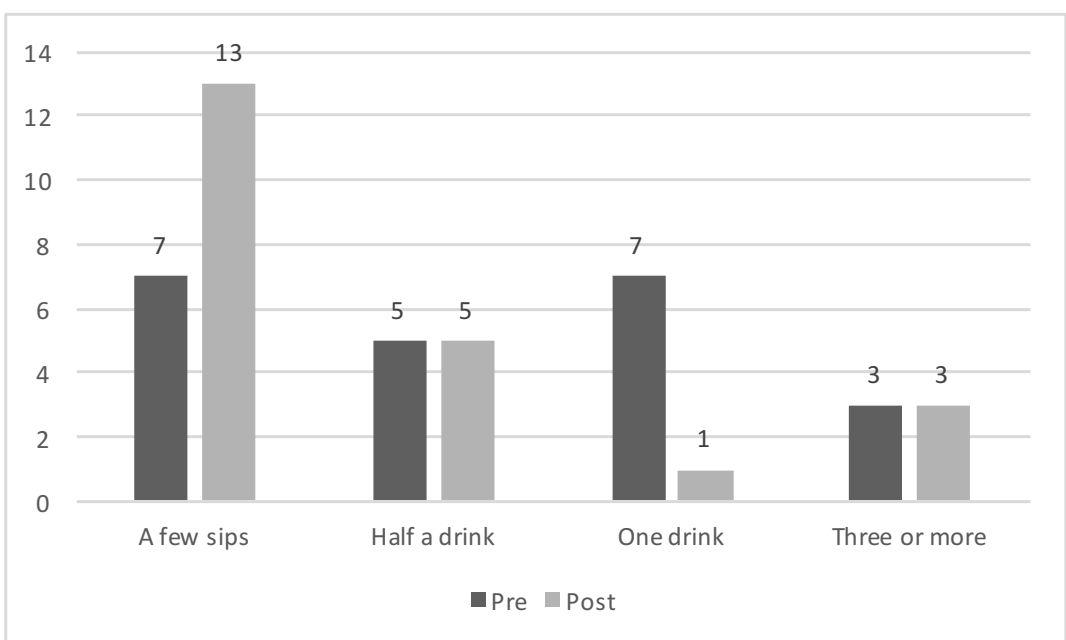

Figure 4. Number of participants reporting amount of alcohol typically consumed

participants who said they had smoked less than one stick from pre to posttest. In contrast, there was a decrease in reports of consuming one drink and a corresponding increase in reports of consuming a few sips of alcohol from pre to posttest, suggesting slight declines in alcohol consumption (see Figure 4). These trends could not be tested 
for statistical significance due to sample size limitations; as such, these results may only be interpreted minimally and require future research with larger sample sizes.

Participant learnings. When asked what they had learned from the program, participants mostly reiterated the knowledge and skills contained in every module, including specific strategies which they were able to practice as a result of the program. This was especially the case for the sessions on stress management, communication, and refusal skills. For instance, a participant said in relation to the module on communication, "effective communication was helpful because I wasn't very good at talking to others before; as aspiring MAPEH teacher, I need social skills and communication so this helped to improve my interactions with other people." Other modules were appreciated more for their motivational impact, particularly the sessions on effects and triggers of substances and goal setting. As a participant shared, "I liked [the module on] looking to the future. I got inspiration for what I want to do and fulfill my dreams." However, there were some sessions, especially on emotion regulation and problem solving, which participants found challenging because of the difficulty of applying them effectively. In the words of a participant, "[I had a hard time with the module on] problem solving in relationships because I still haven't solved misunderstandings properly."

Aside from specific program content, participant responses reflected insights beyond what was specifically mentioned in the modules, such as greater awareness of their strengths, weaknesses, and capacity for improvement. In the words of a participant, "I learned about my being weak because there was a time when I was about to give up, but I became hopeful that I can solve my stress." They also reported social gains, improvements in their self-confidence, and confidence in their capacity to change. Finally, they shared insights about ways by which they can improve themselves, and on the overall importance of the life skills, especially for their future.

Process evaluation. Participants provided feedback on what they liked about the program and its areas for improvement, particularly in the facilitation and program design. In terms of the facilitation, participants' comments revolved around the domains of competence and warmth. That is, they appreciated facilitators' practices that 
increased clarity, such as asking questions and explaining confusing concepts, and modeling positive behaviors. The dimension of warmth was apparent in their comments about facilitators' kindness, calm and positive disposition, fun and use of humor, and genuine approach to teaching. As one participant said, "it's like they genuinely want to teach us." Still, a couple of participants did suggest that facilitators be livelier. One mentioned, "[I wish] facilitators could be more energetic. They're ok, but maybe they can be livelier." Some of their feedback also highlighted practices that demonstrate a combination of warmth and competence, such as checking in on participants, maintaining positive interactions (maayos ang pakikisama) and guiding participants in a non-coercive manner. In the words of a participant, "[names of facilitators] guide us. They don't neglect us and they don't force us."

In terms of the process, participants appreciated the interactive program design apparent in the group activities and sharing, along with a positive learning climate. 'I like that we weren't just listening in the program, we got to share what we knew could be helpful for each of us," shared a participant. They especially liked highly engaging activities, as well as group and dyad sharing. The design of the activities combined with the facilitator's guidance also brought about a positive learning climate where participants listened to each other, appreciated each other's output, and got to know each other and make friends. Still, some suggested that this learning environment can be improved, especially when others would not listen when fellow participants are speaking, laugh at another group's role playing, or tend to dominate the discussion. A participant suggested, "ask for ideas from all the other group members; for example, when there's role playing get the ideas or opinions of the audience."

Our own observations as facilitators and those from the process observers complement this feedback from the participants. We had very low attrition rates, and the few cases of absences were usually because of schedule conflicts with participants' school or family commitments. Moreover, we observed how participants' engagement deepened and became more active as the program progressed. We saw this most clearly in the mindfulness exercise at the beginning of each session, as participants showed greater ease as the weeks progressed. Mirroring participants' comments, it was also evident that they were 
more active and participative during activities rather than lectures or when asked to share their responses individually.

\section{DISCUSSION}

Sulong Kabataan is a community-based life skills program for substance abuse prevention among Filipino urban youth developed through a process of needs analysis, review of existing prevention programs, consultations with stakeholders, and pilot implementation and evaluation. Our pilot implementation suggests the feasibility of the said program, and some positive directions in terms of participant increases in life skills and confidence to refuse alcohol. Participant evaluations as well as our observations as facilitators and from our process observers reveal the value of the interactive design, positive learning climate, and facilitator warmth and competencein contributing to participants' learning and enjoyment. Close coordination with community partners was also crucial as their existing relationship with the participants helped ensure participants' attendance.

\section{Preliminary Evidence of the Program's Effectiveness}

Although the moderate improvement in self-rated life skills appears encouraging, we recommend interpreting this with caution given limitations on the scale properties and sample size for data on reported use and perceived likelihood of future use. Thus, we complemented these results with the qualitative feedback from participants. Participants self-reported greater and more specific learning of life skills with concrete strategies tackled in sessions such as stress management, communication, and refusal skills. The sessions on effects and triggers of substances and goal-setting were evaluated not so much in terms of the skills learned, but for their motivational impact - the session on effects and triggers of substances clarified reasons for avoiding substances, and the module on goal-setting helped participants articulate and look forward to their goals for the future. In contrast, participants reported greater difficulty understanding more abstract and complex life skills of emotion regulation and problem solving. This feedback was addressed by simplifying these modules, 
concretizing and emphasizing the most important elements.

Aside from comprehension issues, participants said that they did not find these two modules on problem solving and emotion regulation as helpful because they were still not able to solve their problems or control their emotions. This suggests an expectation that participating in the program will provide an instant solution, even to difficult situations, possibly reflecting participants' implicit theories about learning and their abilities (Molden \& Dweck, 2006). It may thus help to emphasize the application of life skills as an ongoing process requiring practice rather than instantly learned. Although this is the intention behind the inclusion of in-session skills practice and take-home work in the program, this need for continuous practice can still be communicated more explicitly. We likewise need to highlight that some problems are uncontrollable and should not be adolescents' responsibility to solve.

Aside from changes and learnings related to life skills, participants showed increased confidence in refusing alcohol. We do note the relatively small effect size of these changes, and recommend replicating with larger samples for more robust evidence. Nevertheless, these results may be potentially promising and important with alcohol being the most commonly encountered substance among Filipino adolescents (DRDF \& UPPI, 2014). Mirroring this finding, more participants in our study had already tried alcohol compared to cigarettes, suggesting greater familiarity with situations involving this substance, and lower confidence to refuse alcohol compared to other substances at baseline. That said, exposure to alcohol is more common, leading adolescents to have more opportunities and need to refuse alcohol use.

Given the limitations of the quantitative measures used, more evidence is necessary to make conclusions about the effectiveness of Sulong Kabataan. However, our experience with the pilot implementation demonstrates the feasibility of the program within community settings through close partnerships with key persons in the community. Our coordination with the barangay, especially with the BCPC, helped ensure participants' attendance while also gaining their trust. This was also important in making sure that participants who might have personal or family issues can immediately get the help that they need from the barangay. 


\section{Considering Adolescent Development in the Program Process}

Both the feedback from the participants and observations of process observers and facilitators reflect positive elements and areas for improvement for the program. Notably, the practices and approaches that worked were those most sensitive to adolescent developmental considerations, such as balancing their needs for autonomy and guidance from adults (Choe \& Raymundo, 2001). Consistent with the literature on adolescent prevention programs (Das et al., 2016; Dusenbury \& Falco, 1995; Griffin \& Botvin, 2010) participants appreciated interactive, group-based methods as such approaches are sensitive to adolescents' increasing valuation for peer interactions (Steinberg \& Morris, 2001). Compared to more didactic approaches, this also facilitates attention and comprehension through active engagement in learning, and the opportunity to practice life skills (Durlak, Weissberg, \& Pachan, 2010). Participants also found activities like games and role playing enjoyable, and suggest more of this fun factor in the program. Importantly, role playing scenarios were situated in contexts relevant for Filipino adolescents, such as scenarios involving immediate and extended families (Alampay, 2014; Garo-Santiago et al., 2009), and not just school and peers. Eliciting responses from participants and having them practice specific skills in session may have also contributed to their self-efficacy as they recognize their own capacity to come up with and implement solutions rather than just being told what to do (Midford, 2009).

Just as important in this program design is its execution by the facilitator. Participants appreciated both the competence of facilitators in helping them understand the content of the program, and their warmth through kindness, fun, humor, and encouragement without coercion. Although the program was not necessarily a formal educational setting, such feedback is consistent with research demonstrating student engagement and positive learning outcomes when teachers establish a positive emotional climate through social and emotional competence (Jennings \& Greenberg, 2009; Reyes, Brackett, Rivers, White, \& Salovey, 2012).

Suggested and observed areas for improvement reflect the need 
to account for adolescents' still-developing self-regulation, especially in social contexts (Steinberg, 2005). This includes instances when participants became rowdy and lost their focus, and would laugh at another group's role playing, compromising the positive learning atmosphere. Given this, we recommend regular reminders about the house rules, which participants themselves were asked to create during the beginning of the program. In doing so, there is a balance between providing appropriate structure through reminders of the rules, and autonomy by emphasizing participants' sense of ownership in the rules that they created and agreed on (Vansteenkiste et al., 2012).

\section{Limitations and Recommendations}

As a community-based program, Sulong Kabataan is not intended to be comprehensive in addressing all risk and protective factors involved in substance abuse (Griffin \& Botvin, 2010). The decision to prioritize particular program contents was informed by our focus on Filipino adolescents' developmental concerns and the availability of resources in communities. That said, we recommend complementary approaches, particularly knowledge-based school programs providing specific information about substances, and family programs with parenting training to help address risk and protective factors (Dusenbury \& Falco, 1995).

We likewise note that the pilot implementation described here was conducted by the research team, who also designed the program. We have yet to evaluate the replicability of the program when implemented by those not involved in program design. Nevertheless, our multiple roles put us in a unique position to understand the impact of the program and the areas for improvement. Throughout the sessions, we observed positive shifts in participants' engagement with the activities, and identified important directions to improve ease of use and comprehension of the modules. For instance, highly metacognitive activities were simplified and concretized, as in the case of the emotions and problem solving modules. We likewise created an additional introductory module to orient participants to the program, establish rapport, and set the ground rules for the sessions. Aside from improvements for the manual and modules, we identified points of 
emphasis for training: discussions of adolescent development and the rationale for interactive and supportive approaches, extensive practice of facilitation skills, and instructions for facilitators to reiterate group norms for respect to maintain a positive learning climate.

As a pilot implementation and evaluation, our research has a number of limitations that can be addressed in future iterations of the program. Our pre and posttest design, small sample size, and lack of a control group were not ideal, as the priority of this pilot evaluation was improving and clarifying directions and assessing the feasibility of the program. More than taking the quantitative results as solid evidence of the program's impact, we use this as a source of information for improving the program and its evaluation. For one, participants may have had possible comprehension issues for particular items and lacked familiarity with the research situation. We thus recommend improvement and validation of the scales in both Filipino and English to better assess quantitative outcomes. On a related note, social desirability biases may come into play with the one-on-one interview setting. Thus, we recommend at least quasi-experimental, if not randomized control trials to determine program effectiveness, using reliable measures and data collection procedures. A mixedmethods approach, as was done in this study, will help maximize both comparability of responses and participant meanings and feedback. Future evaluations may include follow-up assessments to measure longer-term changes in substance use, in comparison to youth who were not exposed to the program.

\section{Conclusions}

Based on the pilot implementation and evaluation, we observed the feasibility of the program and its potential positive impact, though we do so with reservations due to limitations in the research design. Many of the youth participants were highly engaged, and provided positive feedback about the program. Participants also showed significant gains in measures of life skills and alcohol refusal confidence. Though several areas for improvement became apparent, we note the strength of the program in creating a positive learning climate through an interactive approach, along with the importance of 
facilitator warmth and competence to support participants' learning and efficacy. Our pilot experience also demonstrates the importance of close coordination with community partners to maximize participant attendance and engagement, as made evident in our low attrition rates.

In this project, we demonstrated the process of developing and evaluating a culturally-appropriate, collaborative, community-based youth prevention program rooted in knowledge about adolescent development. In doing so, we contribute to the body of work on life skills approaches for youth substance abuse prevention programs, and emphasize the utility of developmental psychology in designing programs for adolescents. More concretely, it serves as basis for developing and improving a youth substance abuse prevention program and identifying training needs for future implementation.

\section{AUTHORS' NOTES}

The development and evaluation of this program was funded by the Commission on Higher Education under its K to 12 DARE TO Grantin-Aid program. We also thank all those who made this work possible - our partner LGU and barangay, our research team of interviewers, process observers, and note-takers, the stakeholders who participated in the consultation workshop, our program co-facilitators, and our participants and their parents.

\section{REFERENCES}

Alampay, L. P. (2014). Parenting in the Philippines. In H. Selin (Ed.), Parenting Across Cultures: Childrearing, motherhood and fatherhood in non-western cultures (pp. 105-121). Dordrecht: Springer. http://doi.org/10.1007/978-94-007-7503-9

Botvin, G. J. (2000). Preventing drug abuse in schools: Social and competence enhancement approaches targeting individual-level etiologic factors. Addictive Behaviors, 25(6), 887-897.

Botvin, G. J., \& Griffin, K. W. (2004). Life skills training: Empirical findings and future directions. The Journal of Primary Prevention, $25,211-232$. 
Botvin, G. J., \& Griffin, K. W. (2014). Life skills training: Preventing substance misuse by enhancing individual and social competence. New Directions for Youth Development, 141, 57-65.

Brown, J. M., Miller, W. R., \& Lawendowski, L. A. (1999). The SelfRegulation Questionnaire. In L. VandeCreek \& T. L. Jackson (Eds.), Innovations in clinical practice: A source book (Vol. 17, pp. 281-289). Sarasota, FL: Professional Resource Press.

Chassin, L., Hussong, A., \& Beltran, I. (2009). Adolescent substance use. In R. M. Lerner \& L. Steinberg (Eds.), Handbook of adolescent psychology (pp. 723-764). Hoboken, New Jersey: John Wiley \& Sons, Inc.

Choe, M. K., \& Raymundo, C. M. (2001). Initiation of smoking, drinking, and drug-use among Filipino youths. East-West Center Working Papers Population Series, 108, 1-24.

Das, J. K., Salam, R. A., Arshad, A., Finkelstein, Y., \& Bhutta, Z. A. (2016). Interventions for adolescent substance abuse: An overview of systematic reviews. Journal of Adolescent Health, 59, 561-575.

Demographic Research and Development Foundation and University of the Philippines Population Institute. (2014). 2013 YAFS4 key findings. Quezon City: DRDF and UPPI.

DeWit, D. J., Adlaf, E. M., Offord, D. R., \& Ogborne, A. C. (2000). Age at first alcohol use: A risk factor for the development of alcohol disorders. American Journal of Psychiatry, 157, 745-750.

Duka-Pante, F. G. H. (2017). ASEAN adoption of the drug use prevention international standards. Diliman, Quezon City: ASEAN Training Center for Preventive Drug Education.

Durlak, J. A., Weissberg, R. P., \& Pachan, M. (2010). A meta-analysis of after-school programs that seek to promote personal and social skills in children and adolescents. American Journal of Community Psychology, 45, 294-309.

Dusenbury, L., \& Falco, M. (1995). Eleven components of effective drug abuse prevention curricula. The Journal of School Health, 65(10), 420-425.

Economic and Social Commission for Asia and the Pacific. (2003). Life skills training guide for young people: HIV/AIDS and substance use prevention. New York: United Nations.

Garo-Santiago, M., Mansukhani, R., \& Resureccion, R. (2009). 
Adolescent identity in the context of the Filipino family. Philippine Journal of Psychology, 42(2), 175-193.

Ghosh-dastidar, B., Longshore, D. L., Ellickson, P. L., \& Mccaffrey, D. F. (2004). Modifying pro-drug risk factors in adolescents: Results from Project ALERT. Health Education \& Behavior, 31(3), 318334 .

Gonz, F., Barrera, M., \& Martinez, C. R. (2004). The cultural adaptation of prevention interventions: Resolving tensions between fidelity and fit. Prevention Science, 5(1), 41-45.

Griffin, K. W., \& Botvin, G. J. (2010). Evidence-based interventions for preventing substance use disorders in adolescents. Child and Adolescent Psychiatric Clinics of North America, 19(3), 505-526.

Hawkins, J. D., Catalano, R. F., \& Miller, J.Y. (1992). Risk and protective factors for alcohol and other drug problems in adolescence and early adulthood: Implications for substance abuse prevention. Psychological Bulletin, 112(1), 64-105.

Hsieh, H. F., \& Shannon, S. E. (2005). Three approaches to qualitative content analysis. Qualitative Health Research, 15(9), 1277-1288.

Ibrahim, H. A., Mahmud, S., Abubakar, A., Harazimi, C., \& Abdulkadir, S. (2016). Effect of drug abuse among youth and its impact on learning. IOSR Journal of Pharmacy and Biological Sciences, 11(1), 14-17.

Jennings, P. A., \& Greenberg, M. T. (2009). The prosocial classroom: Teacher social and emotional competence in relation to student and classroom outcomes. Review of Educational Research, 79(1), 491-525.

Kandel, D. B. (2002). Examining the gateway hypothesis. In D. B. Kandel (Ed.), Stages and pathways of drug involvement: Examining the gateway hypothesis (pp. 3-15). New York, NY: Cambridge University Press.

Kumpfer, K. L. Alvarado, R., \& Whiteside, H. O. (2003). Family-based interventions for substance abuse prevention. Substance Use and Misuse, 38(11-13), 1759-1789.

Midford, R. (2009). Drug prevention programmes for young people: Where have we been and where should we be going? Addiction, 105, 1688-1695.

Molden, D. C., \& Dweck, C. S. (2006). Finding "meaning” in psychology: 
A lay theories approach to self-regulation, social perception, and social development. American Psychologist, 61(3), 192-203.

Mrazek, P. J., \& Haggerty, R. J. (1994). Reducing risks for mental disorders: Frontiers for preventive intervention research. Washington, DC: National Academy Press.

Onrust, S. A., Otten, R., Lammers, J., \& Smit, F. (2016). School-based programs to reduce and prevent substance use in different age groups: What works for whom? Systematic review and metaregression analysis. Clinical Psychology Review, 44, 45-59.

Philippine Drug Enforcement Agency. (2015). PDEA Annual Report. Retrieved from http://pdea.gov.ph/our-accomplishments/ annual-reports

Psychological Association of the Philippines. (2017). Katatagan kontra droga sa komunidad. Quezon City: Psychological Association of the Philippines

Quijano, S. B., Quiambao, L. D. C., \& Papa, V. B. (n.d.). Pagpigil sa Pag-abuso ng mga sangkap-kemikal at droga: Modyul ng mga guro sa mataas na paaralan (Mga batang edad 9-11, 12-13, at 14-17). Quezon City, Philippines.

Reyes, M. R., Brackett, M. A., Rivers, S. E., White, M., \& Salovey, P. (2012). Classroom emotional climate, student engagement, and academic achievement. Journal of Educational Psychology, 104(3), 700-712.

Sharma, S. (2003). Measuring life skills of adolescents in a secondary school of Kathmandu: An experience. Kathmandu University Medical Journal, 1(3), 170-176.

Shek, D. T. L., \& Yu, L. (2011). A review of validated youth prevention and positive youth development programs in Asia. International Journal of Adolescent Mental Health, 23, 317-324.

Squeglia, L. M., Jacobus, J., \& Tapert, S. F. (2009). The influence of substance use on adolescent brain development. Clinical EEG and Neuroscience, 40, 31-38.

Steinberg, L. (2005). Cognitive and affective development in adolescence. Trends in Cognitive Sciences, 9(2), 69-74.

Steinberg, L., \& Morris, A. S. (2001). Adolescent development. Annual Review of Psychology, 52, 83-110.

Sussman, S. (1996) Development of a school-based drug abuse 
prevention curriculum for high-risk youths. Journal of Psychoactive Drugs, 28(2), 169-182.

United Nations Office on Drugs and Crime. (2009). Guide to implementing family skills training programmes for drug abuse prevention. New York: United Nations.

Vansteenkiste, M., Sierens, E., Goossens, L., Soenens, B., Dochy, F., Mouratidis, A., ... Beyers, W. (2012). Identifying configurations of perceived teacher autonomy support and structure: Associations with self-regulated learning, motivation and problem behavior. Learning and Instruction, 22(6), 431-439.

Ward, C., Sanders, M. R., Gardner, F., Mikton, C., \& Dawes, A. (2016). Preventing child maltreatment in low- and middle-income countries. Child Abuse and Neglect, 54, 97-107. 